\title{
Sağlık Hizmetlerinde Ürün Çeşitlendirme Politikaları ve Sosyal Projeler Anne Oteli ve Misafir Anne Projesi
}

\author{
Product Diversification Policies in Health Services and Social Projects-Mother Hotel \& Guest \\ Mother Project
}

Onur YARAR, Barış BAĞCIOĞLU

öz

Sağlık sektöründeki büyüme ve pazarlama alanında uzmanlaşmanın hastane hizmetleri pazarlamasını ayrı bir uzmanlık dalı haline getirmiştir. Bu durumda özellikle sağlık hizmetlerinin kullanmış olduğu teknolojideki ilerlemelerin rolü büyüktür. Hekimlerin etkin tanı ve tedavi için modern alet ve cihazlardan yararlanmaları teknolojinin anında takibini zorunlu hale getirmiş ve maliyetleri arttırmıştır. Hastaneler pazar payı pastasından büyük payı alabilmek için fiyat dışı rekabete girmek zorunda kalmışlardır. $\mathrm{Bu}$ da işletme ve yönetim işlevlerinin en uygun çözümlerle yürütülmesiyle gerçekleşebilir.

Çok değişkenli bir çevre içinde, sağlı hizmetlerinin etkin ve verimli olabilmesi, değişkenleri çok yönlü değerlendirmeyi ve kaynak savurganlığını önlemeyi amaçlayan güncel pazarlama yaklaşımılla sağlanabilir. Bu noktada hastanelerin başarısı, pazarlama kavramını yönetimde kullanmaktaki başarılarıyla ölçülecektir.

Sağlık sektöründe pazarlama kavramının bilimsel anlamda uygulamaya konulamamasının sebepleri arasında arz talep dengesizliği önemli yer tutmaktadır. Çünkü, büyük orandaki talep hastanelere hangi şartlarda olursa olsun hizmetlerini sunabilme güvencesi verebilmektedir. Ancak önümüzdeki bir kaç yıl içerisinde açılan hastane sayısındaki ciddi artış, arz talep dengesindeki ciddi değişikliklerin sinyalini vermektedir. Bu nedenle de kuruluşların pazarlarını kaybetmemek ya da yeni pazarlar yaratmak konusunda önlem almaya başlaması gerekmektedir.

Anne ve bebek arasındaki bağın doğumdan hemen sonra geliştiği ve bu bağın kuvvetine göre süt üretiminin artığı göz önüne alındığında annelerin bebeklerinden uzak kalmaması gerektiği ve özellikle annenin; anne sütü üretimi ve bebek ile bağlarının gelişmesi için anne otellerinin bulunması önem arz etmektedir. Bu çalışmada sağlık hizmetlerinde ürün çeşitlendirme politikaları ve sosyal projelerden belki de en önemlisi olan anne oteli ve misafir anne projesinin gerekliliği vurgulanmıştır.

Anahtar kelimeler: Sağlık sektörü, Anne oteli, Hastane

Onur YARAR (更)

Okan Üniversitesi, Sağllk Hizmetleri Meslek Yüksekokulu, İstanbul

e-posta: onuryarar@okan.edu.tr

Barıș BAĞCIOĞLU

Dr. Sami Ulus Kadın Doğum Çocuk Sağlı̆̆g ve Hastalıklarl Eğitim ve Araştırma Hastanesi, Ankara

\begin{abstract}
In there cent days, the development of health sector and the increase of expertisenegotiations in themarketing, makeanotherexpertisefield of marketing of the hospital services. The development of hospital services technology has a big role of it. Because with thedoctors' taking advantage of modern tools and devices for the quick diagnosis and effective cure, make necessary the instant tracking of technology. This naturally increased costs. In this case the hospitals put themselves in the non-price competition to take bigger piece of the cake. This is up to the best usage of operation and management.

In a multivariate environment, effective and efficient health services can be provided with an actual marketing approach which aims to consider the variables in multiple ways and to avoids ourcewasting. At this point the success of the hospitals will be evaluated with the achievement of using the marketing concept at the management.

One of the big reason of not being able to put in to the practice of marketing concept in scientific sense is the imbalance of supply-demand. So this huge demand can give to the hospitals the assurance of providing services no matter what conditions. But in the next few years, the significant increase of new hospitals gives the clue of the serious rise of supply-demand balance. Therefore the organisations must take precautions for not losing markets and creating newmarkets.

Considering that the bond between the mother and the baby developed immediately after birth and the increase in milk production compared to the strength of this bond, the mother should not stay away from her babies; It is important to find maternal mothers for the production of mother's milk and for the development of the bonds with the baby.This study emphasized the necessity of mother hotel and guest mother project which is perhaps the most important of product diversification policies and social projects in health services.
\end{abstract}

Keywords: Health sector, Motherhotel, Hospital 
Hizmet işletmelerinin tamamını ilgilendiren, müșterinin isteklerine ve beklentilerine uygun hizmet sunabilmenin önemi, sağlık hizmetlerinde de söz konusudur. Sağllk hizmetlerinin müşterileri olan hastalar da, ancak kaliteli olarak algıladıkları hizmetlerden memnun kalmaktadırlar. Tüm dünyada olduğu gibi ülkemizde de sağlık gittikçe daha fazla önem verilen bir konu haline gelmekte, ekonomik ve sosyal gelişmenin itici güçlerinden biri olarak kabul edilmektedir. Ancak sürekli olarak artan ihtiyaçlara ve talebe karşın sağlık alanındaki kaynakların sınırlı olması ve verimli kullanılamaması, etkin dağıtımın yapılamaması, birinci basamak sağlık hizmetlerinin etkin kullanılamaması ve bu sağlık hizmetlerinin atlanarak hastanelere başvurulması hastanelerde yığılmalara ve sunulan hizmetlerin kalitesinin düşmesine neden olmakta, dolayısıyla müşterilerin bekledikleri kaliteyi yakalaması ve müşterilerin tatmin edilmesi güçleşmektedir.

Günümüzde batı ülkelerinde tıpta yaşanan gelişmelerin ana sebebi var olan hastalıkların nedenlerini bulmak çabasıyla oluşmuştur. Son yıllarda tıp bilimi ve teknolojisinde yaşanan gelişmeler, hastalıklara dair geniş bir veri elde edilmesini ve deneyim oluşmasını sağlamıştır. Ancak, bu birikim sonucunda örgütlenen "sağlık hizmetleri”nin "sağlık"la ve "sağlığın korunması"yla ilgili olma derecesi tartışmalıdır. Çünkü, bu hizmetler genelde "hastalıkların" ve "hasta olan kişilerin" tedavisi ile, birtakım hastalıkları önleme çabalarılla sınırlı kalmış ve sağlıktan ziyade hastalık ön plana çıkmıştır (1). Sağlık, sadece hastalık ve sakatlı̆̆ın iyileştirilmesi demek değildir. Bu nedenle, hastalığın tanımlanması, sağlık kavramının daha iyi anlaşılmasını sağlayacaktır. Dünya Sağlı Örgütü (WHO) hastalık kavramını "Hastalık, doku ve hücrelerde yapı ve fonksiyon yönünden normal olmayan değişikliklerin ortaya çıkardığı bir durum” olarak tanımlamaktadır (2). Sağlık, fizikî, ruhsal, kültürel ve toplumsal yönlerin sıkı sıkıya bağlı olduğu çok boyutlu bir olgudur. Fizikî hastalık, olumlu ruhsal tavir ve toplumsal destekle dengelenebilir. Bunun yanında duygusal sorunlar, bir insanı fizikî yönden sorun olmamasına rağmen eksiklik duygusuna sürükleyebilir. Sağlığın bu çok boyutlu durumu genellikle birbirini etkiler ve sağlıklı olunduğuna dair en güçlü kanaat, bu boyutlar yeterli derecede dengelendiği ve bütünleştiği zaman ortaya çıkar (3).

Tüm ülkeler ve üzerinde yaşayan toplumlar sağlık sorunlarının, önceliklerinin, olanaklarının ve kaynaklarının farklılık göstermesi, sağlık hizmetlerinin sunumu, finansmanı, örgütlenme ve denetimi konularında birbirinden farklı uygulamalar tercih etmektedirler. $\mathrm{Bu}$ uygulamalar üzerinde genellikle kurumların yaptırım gücü olmamakla birlikte Dünya Sağlık Örgütü etkinliği en fazla olan uluslararası kuruluş durumundadır. Son yüzyıl içinde gelişmiş batı ülkelerinde sağlık alanında çok büyük ilerlemeler kaydedilmiş, çok ileri teknolojiler geliştirilmiş ve ortaya gelişmiş sağlık kuruluşları içeren ulusal sağlık sistemleri çıkmıştır. Hatta globalleşen dünya kavramı içerisinde 2000'li yıllarda ulusal sağlık politikalarının yanında uluslararası ilişkileri daha da geliştirerek dünya sağlık politikaları ve dünya sağlık hizmetleri yönetimi gündeme gelmiştir (4).

Sağlık hizmetleri, hizmet kavramı için geliştirilmiş tüm özelliklere sahip olmakla beraber, bazı farklı özelliklere de sahiptir. Sağlık hizmetlerinin tanımı gereği bu sektördeki kuruluşları belirlemek ve sınıflandırmak oldukça zordur. Sağlık hizmetleri faaliyetleri "kişilerin sağlığının korunması" ve "teşhis, tedavi, bakım" olmak üzere, iki ana grupta toplanmaktadır. Sağlık hizmetleri kişisel olarak ya da kurumsal olarak sunulabilir. Gelişmiş ülkelerde üst düzeylerde kurumsallaşma söz konusu olduğundan, sağllk hizmetlerinin örgütler tarafindan sunulması daha yaygındır. Özellikle, sunulan son hizmetin bir ekip ile üretilmesi ve daha etkin sunulabilmesi kurumsal düşünmeyi ve uygulanmayı zorunlu kılabilmektedir. Bir toplumdaki sağlık göstergeleri, özellikle insan mutluluğunun ana kaynağını teşkil eden sağlıklı olma halini yansıtan temel göstergelerdir. Bu yönü ile, bireylerin sağlıklarını korumak ve toplumların sağlık statülerini geliştirmek önemli bir devlet görevi olarak hükümetleri ilgilendirdiği gibi, fertlerin sağlık hizmetlerine olan taleplerinin giderek artması tüm dünyada sağlik piyasalarının gelişmesine katkıda bulunmaktadır (5)

Gerçekte sağlik hizmetleri bir bütün olmakla birlikte, anlaşılırlığını kolaylaştırmak amacıyla dört ana bölümde incelenmekte ve tanımlanmaktadır. Bu dört bölüm klasik olarak, koruyucu sağlık hizmetleri, tedavi edici sağlık hizmetleri, rehabilite edici sağlık hizmetleri ve sağlı̆̆ın geliştirilmesi hizmetleri seklinde ifade edilmektedir. Sağlik hizmetlerinde ürün (hizmet) ise çekirdek ve genişletilmiş hizmet olarak ikiye ayrılabilir. Çekirdek hizmet, bir hizmetin müşteriye sağladığı faydadır. Sağlık faaliyetleri geniş çapta çekirdek hizmetleri içermektedir. Bu hizmetler tüketicilerin problemlerini çözmek için sunulan soyut faaliyetleri veya süreçleri kapsar. Açık kalp ameliyatı, kanser teşhis programı ve yaşlılık hastalıkları kliniği sağlık işletmelerinin sunduğu hizmetlere genel örnektir (6). Örneğin, çocuk sahibi olmakta güçlük çeken bir çiftin hastaneye başvurma 
nedeni, bekledikleri çekirdek fayda çocuk sahibi olmaktır. Laboratuvar testleri, hatta gerektiğinde cerrahi bir müdahale, bu amaçla verilen elle tutulabilir hizmetlerdir. Söz konusu çift hastaneye geldiklerinde otomobillerini kolayca park edebiliyor, doktorlarını beklemeden görebiliyorlarsa bu hizmetin çoğaltılmış yönüdür (7).

Bir organizasyonun sunduğu ürünlerde ürün karması genişlik, uzunluk ve derinlik olarak sınıflandırılabilir. Sağlık hizmetlerinde ürün karması hastane fonksiyonları ve temel klinik bölümleri açısından kompleks ve dereceli olarak düşünülür. Ürün karması kavramının daha çok pazarlama uyumlu olduğu durum Kotler tarafindan kabul edilen tanım olabilir. Kotler'in tanımında, sağlık hizmetinde ürünler genişlik, uzunluk ve derinliğe göre sınıflandırılmıştır (8). Sağlık işletmesinin başarısı, hizmet bileşimine bağlıdır. Hizmet bileşimi bir hizmet işletmesinin sahip olduğu tüm "hizmet hatlarını" ve bu hatları oluşturan hizmetleri ifade eder. Bir hastane "dar" bir hizmet bileşimine sahip olabileceği gibi, "geniş" bir hizmet bileşimine de sahip olabilir. Sağlık hizmetlerine ayrılan sınırlı kaynakları etkin biçimde kullanabilmek için, sağlık hizmeti sunan birimlerin çeşitli hizmet kalitesi boyutları arasından hastaların önceliklerini belirleyip tanımlamaları ve hasta memnuniyeti için bunları iyileştirmeleri gereklidir. Ancak, birer müşteri olan hastalar, hizmet sunanlardan beklentileri ve çeşitli kalite boyutlarına reaksiyonları bakımından homojen değildir, iyi bir tıbbi bakımın ne olduğu hakkında heterojen bakış açılarına sahiptir. Genel anlamda, hasta ihtiyaç ve istekleri, sağlık hizmetleri sisteminin üzerine kurulduğu, sosyokültürel sistemce şekillendirilir.

Doğum öncesi ve doğum sonrasi yenidoğan'ın bebeklik ve çocukluk dönemlerinde sağlık hizmetlerine erişilebilmesi, sağlık hizmetlerinden faydalanılması, söz konusu hizmetlerin niteliği ve benzer hizmet sunum ölçütlerine sahip olunması anne, bebek ve çocuk ölümlerini önlenmesi ve sağlıklı şekilde gelişimlerinin sürdürülmesi noktasında büyük önem taşır. Günümüzde, basit tedbirler alınarak önlenebilen ve anne ve bebek ölümlerine yol açabilecek birçok unsur halen büyük sorun olarak sağllk sisteminin gündemini meşgul etmektedir. Ülke genelinde bazı bölgelerde kış aylarında yaşanan olumsuz hava şartları nedeniyle ulaşım imkansız hale gelmekte ve doğum zamanı yaklaşmış ya da başlamış olan gebelerin ilgili sağlık kurumuna ulaşması zor olmaktadır.

Sağlık Bakanlığı tarafindan "Sağlıkta Dönüşüm Projesi” kapsamında 16.04.2008 tarih ve 2008/29 sayll Genelge yayınlanarak Ekim 2008 tarihinden itibaren elverişsiz hava ve yol koşullarına sahip yerleşim merkezlerinde yaşayan hamilelerin olası doğum tarihleri yaklaştığında hava ve yol durumu daha elverişli olan yerlere nakledilerek burada konaklamalarının ve uygun hastanelerde doğumlarının gerçekleştirilebilmesi amacıyla "Misafir Anne Uygulaması" programı başlatılmıştır.

Bunun için Halk Sağlığı Müdürlükleri'nce il genelinde, İl Özel İdaresi, Meteoroloji, Karayolları gibi kamu kurum kuruluşları ile iletişime geçilmekte, kötü hava ve yol koşulları nedeniyle yıl boyu veya yılın belirli dönemlerinde yolların kapanması ya da ulaşımın kısıtlı olması ihtimali bulunan yerleşim merkezleri belirlenerek tüm yerleşim yerlerini ve karayollarını gösteren bir risk haritası oluşturulmaktadır. Bu bölgelerdeki bebek, çocuk, gebe, lohusa gibi riskli guruplar belirlenerek takip edilmektedir. Elverişsiz hava ve yol koşullarına sahip yerleşim merkezlerinde yaşayan tüm gebeler olası doğum tarihlerine göre siralanmakta ve gebeliklerinin son ayında doğumun yapılacağı yerin planı gebe ve yakınları ile birlikte incelenerek kesinleştirilmektedir.

Program kapsamında yüksek tansiyon, kalp hastalığı, şeker, tiroid, kan hastalığı gibi kronik hastalığı olan, çoğul gebelik, tekrarlayan düşük, erken doğum riski, kan uyuşmazlığ gibi yüksek risk grubundaki gebeler de önceden belirlenerek 2. veya 3. basamak 55 sağlık kuruluşu tarafindan takip edilmektedir. Misafir edilen annelerin konaklama ve yemek giderlerinin karşılanması amacıyla il genelinde tüm kamu kurum ve kuruluşlarıyla eşgüdümlü hareket edilmekte, özellikle il ve ilçe sosyal yardımlaşma ve dayanışma vakıflarıyla işbirliği yapılmaktadır. Daveti kabul ettiği halde henüz doğumu gerçekleşmeyen gebelerin takiplerine de devam edilmektedir. Bu kapsamda misafir edilen gebeler hastane, yakınının evi, kamu misafirhanesi, otel, motel, pansiyon vb. yerlerde konaklamaktadır (Şekil 1).

Hizmet sunumuna karar verilmesi aşamasında Sağlık Bakanlığının yenidoğan merkezi olan tüm hastanelerde anne oteli kurması çalışmaları da etkili olmuştur. Gelen fikirler, pazar ve talep şartları üretim teknolojisi, finansman kaynakları maliyet ve fayda analizleri detaylı biçimde incelendiğinde anne oteli uygulamasının yenidoğan birimi için faydalı olacağı ve hastane içinde yeni bir hizmet düşüncesi ile gerekli çalışmalar başlatıldı. Bu uygulama ile hem anneler hem de yeni doğanlar rahatlikla hastane içerisinde barınmakta ve hizmet almaktadır.

Günümüzün en karmaşık işletmeleri konumundaki hastanelerde sunulan hizmetler, bir yandan tüm çağdaş toplumlarca bireylerine doğuştan elde edilen bir hak 


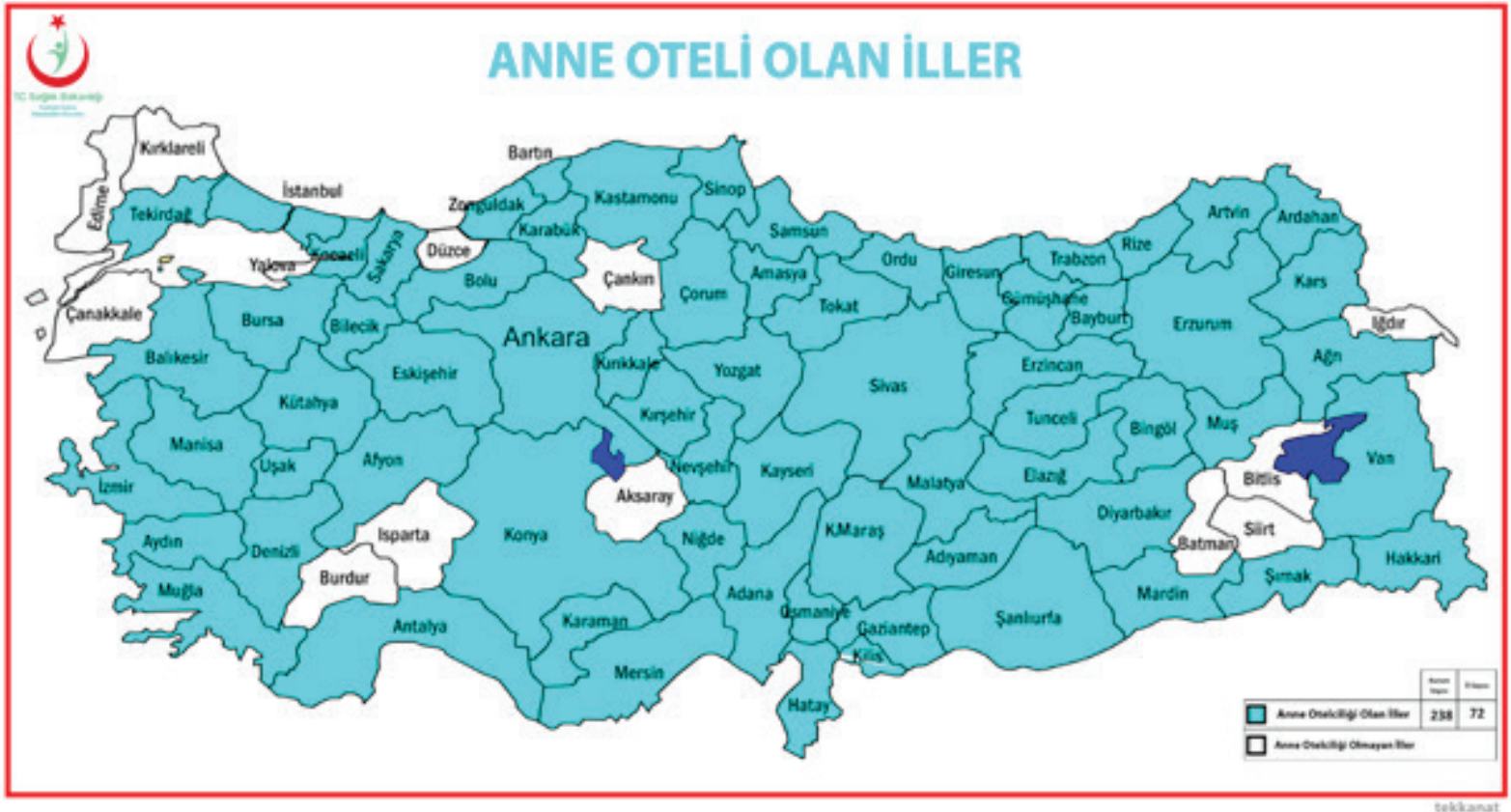

Şekil 1: Türkiye'de Anne Oteli Olan İller (rapor.saglik.gov.tr/TEKKANAT/harita.php'den alınmıştır)

olması yanında diğer yandan da o ülkenin gelişmişlik ve kalkınma düzeyinin tanımlanmasında da kullanılan bir ölçüt konumundadır (9). Ülkemizde hastane işletmeciliği sektörü Cumhuriyetimiz kuruluşunda çıkarılan yasal mevzuat paralelinde organize edilmiş olup yönetilen kamu hastanelerinden oluşmakta ve bu hastanelerde her platformda kalite ve verimlilik sorunları dile getirilmektedir. Ülkemiz kamu hastaneleri bir yandan müşterileri konumundaki hastalarına sunulan hizmeti değerlendirme konusundaki güçlüklerini diğer yandan da objektif kriterlerle belirlenmiş performanslarını değerlendirebilecekleri bir yapı olmaması nedeniyle şifa kapıları yerine zulüm kapıları konumuna gelmektedir. Sağlık hizmetlerinde, hizmetin tüm etkenleri uyumlu bir yapı arz eder. Sağlık hizmetlerinde kalitenin ön şartı, sağlam bir yönetim modeli ve organizasyon içerisinde, işlerin, yapacağı kişinin, yapılacağı zamanın, yapılacağı yerin, yapılırken kullanılacak araçların ve kullanılacak yöntemin bilinir olmasıdır.

Hastanelerde Toplam Kalite Yönetiminin uygulanmasıyla birlikte, yetersiz olan hastane kaynaklarının etkin bir şekilde kullanılması, maliyetlerin düşürülmesi, diğer işletmelerle rekabet etme imkanının artması, hasta ve çalışan memnuniyetinin artırılması mümkün hale gelmektedir. Hizmet sunumunda kalitenin sağlanması ile çalışanların iş tatmini ve motivasyonunun, yönetim ve organizasyon yöntemlerinin modernizasyonunun, karar mekanizmalarında akılcılığın, bilgi sistemlerinde belgelemeye ağırlık verilmesinin ve iletişim mekanizmasının işlerliğinin sağlanması beklenilmektedir. Ayrıca hasta memnuniyeti, ekip çalışması yoluyla takım ruhunun gelişmesi ve en önemlisi de kalitenin artırılması yoluyla "Kamu Yararı" çerçevesinde faydalar sağlanması hedeflenmektedir. Çalışanlar kalite yönetimi felsefesine inançlı ve gönüllü bir biçimde katılmalıdır. Özellikle doktorların kalite çalışmalarında aktif olarak yer almaları gerekmektedir. Doktorlar, sürekli gelişme süreçleri, kalite çemberleri ve eğitim süreçlerinin ayrılmaz parçası olmalıdır. Sağlık hizmetlerindeki kalite geliştirme çabaları hastanın ve süreç içerisinde yer alan diğer kişilerin tatminine yöneliktir.

Türkiye'deki sağlık hizmeti sunum modeli göz önüne alındığında, kalitenin sürekli iyileştirilmesi programının oluşturulması için; mevcut kalite düzeyinin ölçülmesi, kalite düzeyinin sürekli iyileştirilmesi, entegrasyonun sağlanması, bölgesel farklılıklar, sorumluluk ve aktivitelerin paylaşımı, hastanın ve sağlik personelinin memnuniyeti, toplumun bilinçlenmesi ve işbirliği gibi bazı şartların oluşturulması gerekmektedir. Sağlık hizmetlerinde, hizmeti oluşturan tüm unsurlar entegredir. Sağllk hizmetlerinde kaliteden söz edebilmek için öncelikle; sağlam bir yönetim modeli ve organizasyonun var olması, işlerin, kim tarafından, ne zaman, nerede, hangi araçlar kullanılarak, ne yöntemle yapıldığının bilinmesi büyük önem taşımaktadır. Sağlık hizmetlerinin kalitesi, sadece sağlık hizmetleri sağlayıcıları ve hastalar açısından değil, hükümetler açısından da önemli 
bir konudur. Kaliteli sağlık hizmetleri, insanların daha sağlıklı ve daha mutlu olmalarına katkıda bulunacaktır.

İnsan hayatında sevginin ilk belirişi anne ve bebek arasındaki derin bağdan kaynaklanmaktadır. Ülkemizde doğa şartlarının ve bölgesel coğrafi şatların zor olduğu yerlerde hem anne sağlığı hem de bebek sağlığı açısından misafir anne projesi son derece fayda sağlayacağı göz önünde bulundurulmalı ve bu uygulama teşvik edilerek anne ve bebek ölümlerinin önüne geçilmeye çalışılmalıdır. Bebeğin anneden uzun süre ayrı kalmasının bebeğin mental, motor ve duygusal gelişimini olumsuz etkilediği saptanmıştır. Çocuğun gelişme ve öğrenmesinde anneye yakınlığın rolü çok büyük olduğuna göre annenin ve bebeğin ilişkisine yardımcı olmak sağlık personelinin görevleri arasındadır. Anne otelinin ve misafir anne projesi günümüzde gelişmesi için Sağlık Bakanlığının bu konu hakkında gereken eğitimler verilmesi gereklidir.

Anne ve bebek arasındaki bağın doğumdan hemen sonra geliştiği ve bu bağın kuvvetine göre süt üretiminin artığı göz önüne alındığında annelerin bebeklerinden uzak kalmaması gerektiği ve özellikle annenin; anne sütü üretimi ve bebek ile bağlarının gelişmesi için anne otellerinin bulunması ve misafir anne projesinin gelişimi önem arzetmektedir.

\section{KAYNAKLAR}

1. Yerebakan M. Özel Hastaneler Araştırması Mevcut Durum, Sorunlar ve Çözüm Önerileri, İstanbul Ticaret Odası Yayın No:2000-26, İstanbul, 2000: 13

2. Joint ILO/WHO Committee on OccupationalHealth, International LabourOrganizationand World HealthOrganization, 1951.

3. Kızılçelik S. Türkiye'nin Sağlı Sistemi Bir Medikal Sosyoloji Denemesi, Saray Kitabevleri, İzmir, 1996: 80-81

4. Odabaşı Y. Sağlık Hizmetleri Pazarlaması, Anadolu Üniversitesi Yayın No:799, Açıköğretim Fakültesi Yayın No:409, Eskişehir, 1994: 26

5. Özgirin K, Taş Y. Hastane Yönetiminde Kalite Uygulamaları ve Toplam Kalite Yönetimi Projesi Kapsamında Personel Memnuniyeti Ölçme Çalışması, Sağlık Hizmetlerinde Toplam Kalite Yönetimi ve Performans Ölçümü Sempozyumu, Ankara, 1996: 34.

6. Berkowitz E.N. Essentials of HealthCare Marketing, Gaithersburg, Maryland: An Aspen Publication, 1996: 201202.

7. Karafakioğlu M. (1998): Sağlık Hizmetleri Pazarlaması, İstanbul: İstanbul Üniversitesi İşletme Fakültesi Yayın No:271, İstanbul, 1998: 118.

8. France, K R, Grover, R. "What Is the Health Care Product?, Journal of Health Care Marketing, Cilt: 12, Say1: 2, 1992: 35.

9. http://www.merih.net/m1/wusah04.htm- (Erişim tarihi: 22.1.2015) 
